\section{Case Reports in Ophthalmology}

Case Rep Ophthalmol 2020;11:486-492

DOI: 10.1159/000509338

Published online: August 12, 2020

(C) 2020 The Author(s)

Published by S. Karger AG, Basel

www.karger.com/cop

This article is licensed under the Creative Commons Attribution-NonCommercial 4.0 International License (CC BY-NC) (http://www.karger.com/Services/OpenAccessLicense). Usage and distribution for commercial purposes requires written permission.

\title{
Scanning Electron Microscopy Observations of Loa loa (Nematoda)
}

\author{
Jens Anibal Juul ${ }^{\mathrm{a}} \quad$ Vegard Asgeir Forsaa $^{\mathrm{a}}$ Tor Paaske Utheim ${ }^{\mathrm{a}}$ \\ Endre Willassen ${ }^{\mathrm{b}}$ \\ aDepartment of Ophthalmology, Stavanger University Hospital, Stavanger, Norway; \\ ${ }^{b}$ Department of Natural History, University of Bergen, Bergen, Norway
}

\author{
Keywords \\ Loa loa $\cdot$ Microfilaria $\cdot$ Filariosis $\cdot$ Loiasis
}

\begin{abstract}
We present a case report of periocular Loa loa. The key feature of $L$. loa distinguishing it from other human filarial parasites are cuticular bosses, which are presented in images from a light microscope and a scanning electron microscope. The cuticular bosses could be divided into three subtypes not previously described.

\section{Introduction}

Loiasis is a parasite infection by the filarial nematode Loa loa. Adult L. loa worms live in human subcutaneous and connective tissues, where they reproduce. Migration to the subconjunctival space is considered pathognomonic [1]. Its lifecycle is strongly linked with two groups of host organisms: humans and flies of the genus Chrysops. The fly takes up microfilariae circulating in the bloodstream of the human host via its bite, and the microfilariae mature into an infective larval stage in the fly itself $[2,3]$. When the fly bites a new host, the larvae may re-enter the human vascular system. Maturation into adult worms takes about 3 months [3]. The life expectancy of an adult worm is about 9 years, but individuals are thought to be able to survive for as long as 15-20 years [2-4]. Female worms produce eggs that develop into microfilariae, about 250-300 $\mu \mathrm{m}$ in length. A single female can release an average of 10,000- 
22,000 microfilaria per day [5], and more than 100,000 parasites per $\mathrm{mL}$ blood have been recorded in an infected individual [3]. Loiasis is endemic to central Africa and affects more than 10 million people [2]. About three-quarters of all cases of imported loiasis to Europe and the USA during 1986-2011 were traceable to Cameroon, Gabon, Nigeria, or the Democratic Republic of Congo [6]. Reports of recent occurrences outside endemic areas have spurred speculation that loiasis is expanding due to increased mobility of human populations [6].

\section{Case Presentation}

A healthy 42-year-old Norwegian woman with no prior medical history, who had holidayed in Cameroon a few years earlier, experienced several occasions of a moving sensation over 2 years, both subconjunctival and in the palpebrae of both eyes. In addition, transient skin lesions resembling Calabar swellings had occurred in different locations. In the months before she made contact, the frequency of the eye symptoms increased and culminated in pain from the left eye. At presentation later the same day, the symptoms had decreased, and no worm was visible. The only findings were moderate conjunctival chemosis and hyperaemia. Visual acuity was $20 / 20$, and there was no intraocular inflammation. The next day she presented with a moving subconjunctival worm in her left eye, which could be removed in parts. The clinical findings suggested a nematode infection, but due to pregnancy, antihelmitic treatment was not prescribed. The results of work-up showed the following: normal immune status, no microfilaria in repeated peripheral blood smears, no parasites found in stool examination, elevated eosinophil count of $10.94 \times 10^{9} / \mathrm{L}$ (normal values: $0.03-0.44 \times 10^{9} / \mathrm{L}$ ), leucocytosis, $21.4 \times 10^{9} / \mathrm{L}$ (normal values 3.9-10.4 $\times 10^{9} / \mathrm{L}$ ), and highly positive filaria antibodies ELISA of 112 units (cut-off 17). Four months later, postpartum, she made contact again because of a painful sensation and visualization of a subcutaneous moving object in the upper right eyelid. There was no bulbar involvement. After subcutaneous anaesthesia, an approximately $20-\mathrm{mm}$, transparent, alive, vividly moving worm was extracted from the upper eyelid. Antihelmitic treatment with diethylcarbamazine citrate was initiated 1 week later and no further L. loa manifestations have been evident since. The visual function remained unchanged during follow-up. The worm was identified as an adult male L. loa. Species identification was based on Anderson et al. [7], particularly observing the presence of cuticular "bosses", a key characteristic separating Loa species from Dirofilaria species, which may also cause cutaneous or ophthalmic disease.

We observed, in agreement with Eberhard and Orihel [5] that the tail of L. loa was relatively weakly flexed (Fig. 1a, c; 2a, g) and not coiled in a spiral as in males of lymphatic filarial species such as Wuchereria bancrofti [8] and Brugia pahangi [9]. Spiral tails have also been illustrated for Dipetalonema [10] and Dirofilaria species [11], which are other causes of human ocular filariasis. A coiled tail is less developed in the eye worms of Onchocerca [12]. However, Oncocerca may be identified by their characteristic cuticular patterns of transverse rings, known as rugae $[9,13]$. Geographically overlapping and sometimes infecting humans concomitantly with Oncocerca and Loa are Mansonella [14]. Adult Mansonella species are recognizable by the characteristic transverse bands of the area rugosa anterior to the cloaca, very long male spines, and flapped tail tips supported by hypodermal branches [12].

We noted that the cuticular bosses (Fig. 1d, 2a), used as a key characteristic for distinguishing Loa species from other genera in the subfamily Dirofilariinae [7], were of at least three different types (Fig. 2d-f). The dominant type (Fig. 2b, e) had slightly raised domes with 


\section{Case Reports in Ophthalmology}

marked ellipsoid delineations. We also observed rounded tubercles (Fig. 2d) and smaller rounded domes with microstructural surfaces similar to that of the surrounding area (Fig. 2f).

Our specimen had relatively modest caudal papillae. Although visible under phase microscopy (Fig. 1c), the appearance under scanning electron microscope (SEM) was somewhat faint compared with previously published micrographs [9], and more similar in size to those pictured by Wong and Brummer [11] for Dirofilaria species. However, the longitudinal ridges running along the body surface of our specimen (Fig, 1d; 2a, d, e, g, h) were relatively smooth and did not have the slightly beaded pattern observed in Dirofilaria [11].

\section{Methods}

Images of the worm were captured using Leica M205 C and Leica DM 6000 B microscopes. In the latter, the worm was mounted on a microslide and embedded in glycerol. For SEM, the worm was treated for 1 min in distilled water with a small piece of a Corega ${ }^{\mathrm{TM}}$ denture cleaning tab and washed to remove external remnants of host serum. The worm was subsequently transferred to $96 \%$ ethanol, air-dried, mounted on a stub, and coated with gold-palladium for examination with a ZEISS SUPRA 55VP scanning electron microscope.

\section{Discussion}

We report the first subcutaneous removal of $L$. loa from the eyelid in Norway. It is reasonable to believe that increased travel and migration will result in a greater chance of encounters outside Africa [6]. Therefore, it is important for ophthalmologists to be aware of the condition, its presentation, and the patient's travel history. The principal vector species of loiasis are the African tabanid flies Chysops silacea and $C$. dimidiate, while a third species, $C$. distinctipennis has been suggested as the vector in Central Africa [15]. Although laboratory experiments have demonstrated that an American species of Chrysops was able to host Loa larvae [16], it seems very unlikely that our patient was infected by any of the seven Chrysops species recorded from Norway [17]. Several other nematodes are known to affect the human eye. Human filarial parasites, such as W. bancrofti, Brugia malayi, and Onchocerca volvulus are well studied due to their clinical severity or socio-economic impacts. Besides L. loa, species of Acanthocheilonema, Dirofilaria, Mansonella, Pelecitus, and Thelazia callipaeda are among the nematode worms that may present as adults to the ophthalmologist [18]. To understand the source of the parasite infection, the health risks of the affected patient, and the best options for treatment, it is critical that the species is correctly identified and not confused with other candidate species.

Cuticular bosses are key characteristics for $L$. loa. They are clearly visible on the presented light microscopy images. In the SEM images a classification of cuticular bosses in at least three subtypes was possible, and to our knowledge this has not been described previously.

\section{Acknowledgements}

Katrine Kongshavn kindly helped with the SEM. 


\section{Case Reports in Ophthalmology}

\section{Statement of Ethics}

The affected subject provided informed consent to publish their case including the publication of images.

\section{Disclosure Statement}

The authors have no conflicts of interest to declare.

\section{Funding Sources}

The authors have no funding sources to declare.

\section{Author Contributions}

J.A.J. carried out the surgical procedure and follow-up of the patient. E.W. was responsible for the identification and description of the specimen. J.A.J., E.W., V.A.F., and T.P.U. contributed to the writing of the manuscript. All authors read and approved the final manuscript.

\section{References}

1 Padgett JJ, Jacobsen KH. Loiasis: African eye worm. Trans R Soc Trop Med Hyg. 2008 Oct;102(10):983-9.

2 Whittaker C, Walker M, Pion SD, Chesnais CB, Boussinesq M, Basáñez MG. The Population Biology and Transmission Dynamics of Loa loa. Trends Parasitol. 2018 Apr;34(4):335-50.

3 Ryan ET, Hill DR, Solomon T, Endy TP, Aronson N. Hunter's tropical medicine and emerging infectious diseases. Tenth edition. Amsterdam: Elsevier; 2020.

4 Boussinesq M. Loiasis: new epidemiologic insights and proposed treatment strategy. J Travel Med. 2012 May-Jun;19(3):140-3.

5 Eberhard ML, Orihel TC. Loa loa: output of microfilariae in single pair infections. Trop Med Parasitol. 1986 Dec;37(4):369-74.

6 Antinori S, Schifanella L, Million M, Galimberti L, Ferraris L, Mandia L, et al. Imported Loa loa filariasis: three cases and a review of cases reported in non-endemic countries in the past 25 years. Int J Infect Dis. 2012 Sep;16(9):e649-62.

7 Anderson RC, Chabaud AG, Willmott S; Commonwealth Institute of Helminthology. Keys to the nematode parasites of vertebrates. Archival volume. Wallingford: CABI; 2009. Available from: https://doi.org/10.1079/9781845935726.0000.

8 Araujo AC, Figueredo-Silva J, Souto-Padrón T, Dreyer G, Norões J, De Souza W. Scanning electron microscopy of adult Wuchereria bancrofti (Nematoda: filarioidea). J Parasitol. 1995 Jun;81(3):468-74.

9 Gibbons LM; Commonwealth Institute of Parasitology. SEM guide to the morphology of nematode parasites of vertebrates. Farnham Royal: C.A.B. International; 1986.

10 Huynh T, Thean J, Maini R. Dipetalonema reconditum in the human eye. Br J Ophthalmol. 2001 Nov;85(11):1391-2.

11 Wong MM, Brummer ME. Cuticular morphology of five species of Dirofilaria: a scanning electron microscope study. J Parasitol. 1978 Feb;64(1):108-14.

12 Bain O, Mutafchiev Y, Junker K, Guerrero R, Martin C, Lefoulon E, et al. Review of the genus Mansonella Faust, 1929 sensu lato (Nematoda: Onchocercidae), with descriptions of a new subgenus and a new subspecies. Zootaxa. 2015 Feb;3918(2):151-93.

13 Mutafchiev Y, Dantas-Torres F, Giannelli A, Abramo F, Papadopoulos E, Cardoso L, et al. Redescription of Onchocerca lupi (Spirurida: Onchocercidae) with histopathological observations. Parasit Vectors. 2013 Oct;6(1):309. 
Case Reports in Ophthalmology
Case Rep Ophthalmol 2020;11:486-492

(c) 2020 The Author(s). Published by S. Karger AG, Basel DOI: 10.1159/000509338 www.karger.com/cop

Juul et al.: SEM Observations of $L$. loa

14 Wanji S, Tendongfor N, Esum M, Ndindeng S, Enyong P. Epidemiology of concomitant infections due to Loa loa, Mansonella perstans, and Onchocerca volvulus in rain forest villages of Cameroon. Med Microbiol Immunol (Berl). 2003 Feb;192(1):15-21.

15 Service MW. A guide to medical entomology. London: The MacMillan Press Ltd; 1980. https://doi.org/10.1007/978-1-349-16334-2.

16 Orihel TC, Lowrie RC Jr. Loa loa: development to the infective stage in an American deerfly, Chrysops atlanticus. Am J Trop Med Hyg. 1975 Jul;24(4):610-5.

17 Falck M. The horse flies (Diptera, Tabanidae) of Norway. Nor J Entomol. 2014;61:219-64.

18 Otranto D, Eberhard ML. Zoonotic helminths affecting the human eye. Parasit Vectors. 2011 Mar;4(1):41. 
Case Reports in Ophthalmology
Case Rep Ophthalmol 2020;11:486-492

DOI: $10.1159 / 000509338$

C 2020 The Author(s). Published by S. Karger AG, Basel www.karger.com/cop

Juul et al: SEM Observations of $L$. loa
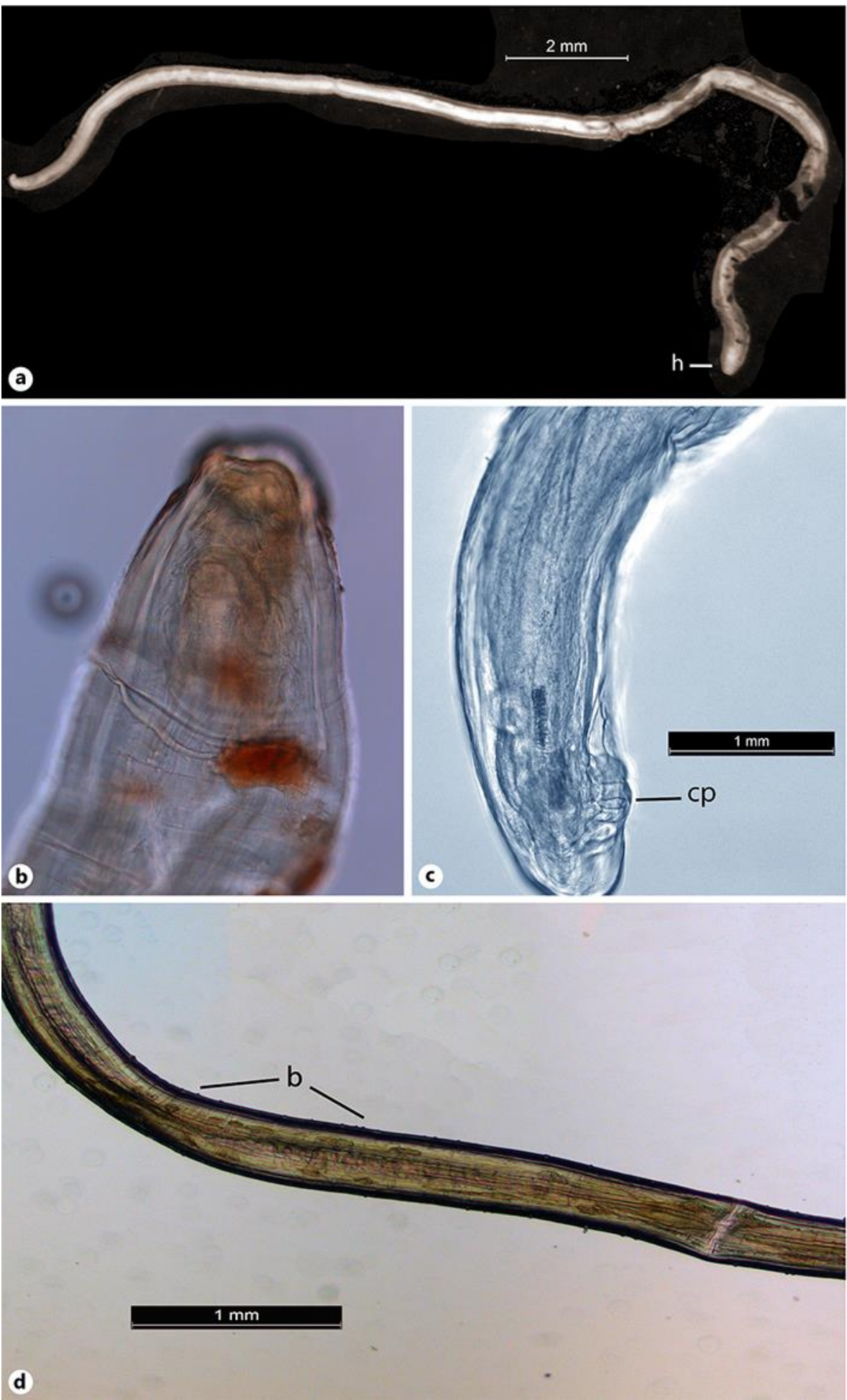

Fig. 1. Light microscopy. a Loa loa full-length with head (h) and weakly bent tail. b Head region. c Tail region showing caudal papillae (cp) and internal genital spines. $\mathbf{d}$ Mid body region with bosses (b) and longitudinal cuticular ridges. 
Case Reports in Ophthalmology
Case Rep Ophthalmol 2020;11:486-492

DOI: $10.1159 / 000509338$

(C) 2020 The Author(s). Published by S. Karger AG, Basel www.karger.com/cop

Juul et al.: SEM Observations of L. loa
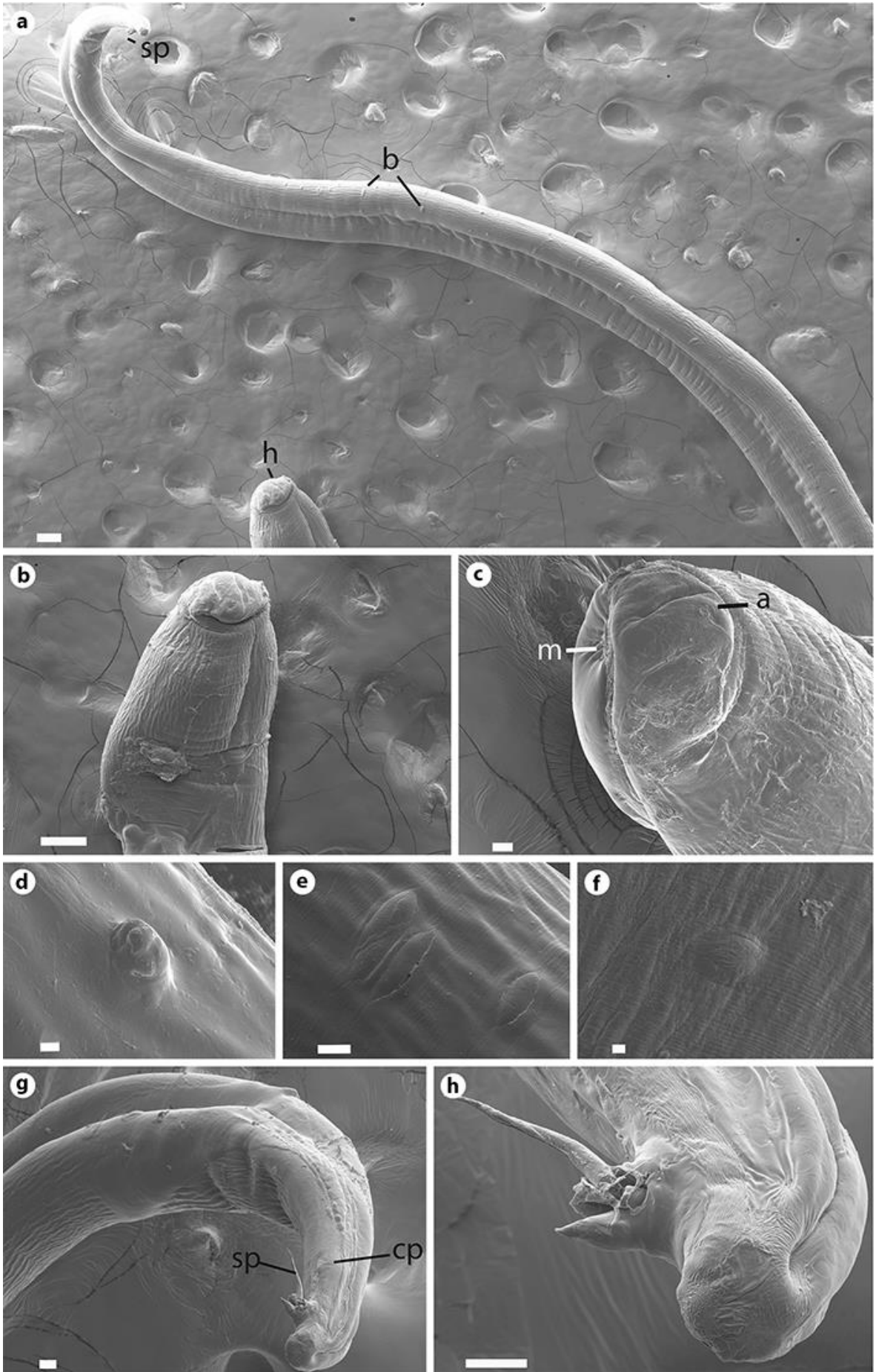

Fig. 2. Scanning electron microscopy. a Loa loa with head (h), spines (s), and ellipsoid bosses (b) (scale = $100 \mu \mathrm{m})$. $\mathbf{b}$ Head and cervical region (scale $=100 \mu \mathrm{m})$. $\mathbf{c}$ Oral region with mouth $(\mathrm{m})$ amphid $(\mathrm{a})$ (scale $=$ $20 \mu \mathrm{m})$. $\mathbf{d}$ Tubercle (scale $=3 \mu \mathrm{m})$. e Ellipsoid bosses (scale $=10 \mu \mathrm{m}) . \mathbf{f}$ Dome-shaped boss $(\mathrm{scale}=2 \mu \mathrm{m})$. $\mathbf{g}$ Tail region with caudal papillae (cp) and genital spines (sp) (scale $=20 \mu \mathrm{m}) . \mathbf{h}$ Genitalia and caudal end (scale $=20 \mu \mathrm{m}$ ). 